surgical services to avoid escalation of this critical public health issue.

\section{IMPLEMENTATION OF EVIDENCE-BASED EXERCISE IN PROMOTION OF MOBILITY IN STRENGTH IN OLD AGE PROGRAMME}

Elina Karvinen, Pirjo Kalmari, Päivi Topo. The Age Institute, Finland

\subsection{6/injuryprev-2016-042156.497}

Backround In the ageing societies one of the main aims of social and health policies is to find the best ways in promoting the independent living of old people. The Strength in Old Age Programme aims to promote the mobility of older adults $(75+)$ with decreased functional capacity by physical exercise. The programme is coordinated by the Age Institute and financed by Finland's Slot Machine Association, Ministry of Education and Culture, and Ministry of Social Affairs and Health.

Methods 38 municipalities (2010-2015) were chosen for the three-year development in order to implement the best practices in exercise counselling, strength and balance exercise and outdoor exercise. The municipalities committed to implementation through multisectoral collaboration without extra funding. The sectors included municipal social, health care and sports services, and NGOs. Each sector appointed one of their regular staff to coordinate and cooperate with the Age Institute. Local cross-sectoral work was supported by the mentoring of the Age Institute including counselling, training and development tools.

Results The number of exercise groups (1500) and participating old people (22 044) in the target group doubled. In total, 70 percent of the target population living in the 38 municipalities have been reached. Based on the assessment of 2,000 participants, strength and balance were improved in 53\% and maintained in $38 \%$ during the exercise period. A cross-sectoral cooperation group and the implementation of best practices was established in 30 municipalities, and in 36 municipalities the health enhancing physical activity of old people was included in the welfare strategies.

Conclusions With the help of the three-year mentoring including training and support for cross-sectoral collaboration it is possible to implement research-based good practices within older people's physical exercise and improve the mobility of older adults.

\section{INVESTIGATING FALL-RELATED INJURY HOSPITALISATIONS FOR OLDER INDIGENOUS PEOPLE IN AUSTRALIA}

${ }^{1,2} \underline{C}$ Lukaszyk, ${ }^{3} \mathrm{~L}$ Harvey, ${ }^{3} \mathrm{~J}$ Close, ${ }^{1} \mathrm{R}$ Ivers. ${ }^{1}$ The George Institute for Global Health, Australia; ${ }^{2}$ The University of Sydney, Australia; ${ }^{3}$ Neuroscience Research Australia

\subsection{6/injuryprev-2016-042156.498}

Background It is estimated that one in three people aged 65 years and above fall each year in Australia. Despite high injury rates across Australia's Indigenous population and worse general health outcomes for older age groups, little is known about the incidence, nature and outcomes of fall-related hospitalisations specifically in older Indigenous people.

Methods Linked hospitalisation and death records for individuals aged 50 years and over admitted to a hospital in New South Wales, Australia for a fall-related injury were analysed. Indigenous status was identified if reported on at least $50 \%$ of an individual's hospitalisation records. Descriptive statistics, agestandardised hospitalisation rates and rate-ratios (ARR) were calculated. Trends over time were analysed using negative binomial regression.

Results Of the 312,785 fall-related injury hospitalisations, $0.7 \%$ reported to be Indigenous. Compared to non-Indigenous people, a higher proportion of Indigenous people were aged 50-55 years (23.7\% vs $5.2 \%, \mathrm{p}<0.0001)$, admitted for a head injury $(23.8 \%$ vs $19.0 \%, \mathrm{p}<0.0001)$ whilst a lower proportion were admitted for hip fracture $(9.2 \%$ vs $18.4 \%, \mathrm{p}<0.0001)$. Age-adjusted 30 day mortality was lower for Indigenous people (1.9\% vs $4.2 \%$, $\mathrm{p}=0.0002)$. Indigenous people had consistently lower hospitalisation rates for fall-related injury than non-Indigenous people (ARR 0.83; 95\% CI: 0.78-0.87, p < 0.0001). However, fall injury rates for Indigenous people increased at a greater rate of 5.6\% (95\% CI: 3.6-7.6, p < 0.0001) per annum compared to $2.6 \%$ (95\% CI: 2.1-3.1, p < 0.0001) per annum for non-Indigenous people.

Conclusions Although fall-related injury rates appeared to be relatively low in Indigenous patients, this study demonstrates that fall injury is rapidly becoming a growing issue for Australia's older Indigenous population.

\section{KAATUMISSEULA ${ }^{\circledR}-$ IMPLEMENTATION OF EVIDENCE- BASED FALL PREVENTION FOR COMMUNITIES}

Saija Karinkanta, Elina Ahlstedt-Kivelä, Pekka Kannus, Tommi Vasankari, Harri Sievänen. The UKK Institute for Health Promotion Research, Finland

\subsection{6/injuryprev-2016-042156.499}

Background Fall injuries are a growing global health problem in older adults. Compelling scientific evidence shows that every third fall can be prevented. Effective measures need to be based on knowledge of individual fall risk. This underscores importance of fall risk screening. In Finland, risk screening and preventive measures are not used systematically. Thus, implementation of evidence-based methods for communities is necessary. In the present economic situation, resources of the third (voluntary and non-profit) sector (NGOs) should also be utilised.

Objective The main objective of KaatumisSeula ${ }^{\circledR}$ project is to create local models for fall risk screening and implementing evidencebased preventive measures. The models are based on co-operation between local public sector and NGOs. Primary risk screening is offered for older people by public sector and NGOs. People with high fall risk are referred to comprehensive assessment of individual fall risk and tailored implementation of fall prevention measures by educated health care professional(s). This approach is based on the multifactorial Chaos Falls Clinic Study. NGOs play a central role in not only screening but also informing about fall prevention measures and offering accessible balance and strength training - the most effective single intervention in fall prevention.

Results The project models are now in operation in 2 municipalities, and the third is starting. NGOs are active and keen in their role. Two Falls Clinics have started and high risk older adults have found their ways to the multifactorial assessment. Public sector and NGOs have received education. New exercise groups have been established and fall prevention materials have been given. So far, the most challenging task has been implementation of systematic fall screening for public sector.

Conclusions KaatumisSeula ${ }^{\circledR}$ is a feasible approach to screen the fall risk of older adults and implement preventive measures in community. 


\section{THE EFFECT OF COMORBIDITY AND GENDER ON IN- HOSPITAL MORTALITY IN PATIENTS WITH FALLS: RESULTS FROM A LARGE ASIAN TERTIARY CARE HOSPITAL}

${ }^{1,2}$ Yong Yang, ${ }^{3}$ Emily Ho, ${ }^{2,4}$ Julian Thumboo, ${ }^{2}$ Truls Østbye, ${ }^{5}$ Yee Sien $\mathrm{Ng}^{6}{ }^{6} \mathrm{Chern}$ Hui Jeffrey Fong, ${ }^{2,7}$ Kok Yong Fong. 'Department of Epidemiology, Medical Board, Singapore General Hospital, Outram Road, Singapore 169608; ${ }^{2}$ Duke-NUS Graduate Medical School, 8 College Road, Singapore 169857; ${ }^{3}$ Department of Endocrinology, Singapore General Hospital, Outram Road, Singapore 169608; ${ }^{4}$ Department of Rheumatology and Immunology, Singapore General Hospital, Outram Road, Singapore 169608; ${ }^{5}$ Department of Rehabilitation Medicine, Singapore General Hospital, Outram Road, Singapore 169608; ${ }^{6}$ Healthcare Analytics, Integrated Health Information Systems (IHIS), SingHealth Corporate Office, 6 Serangoon North Ave 5, Singapore 554910; ${ }^{7}$ Medical Board, Singapore General Hospital, Outram Road, Singapore 169608

\subsection{6/injuryprev-2016-042156.500}

Background Falls and fall-related injuries are a major public health issue among older adults worldwide. Causes and prognostic indicators of death in older patients with fall are lacking in Asian countries, especially in local older population. We aimed to assess the disease burden of fall and the usefulness of Charlson comorbidity index (CCI) and male sex as risk adjusted hospital mortality predictors in older Asian patients with fall using hospital administrative database. Methods: Historical cohort study of hospital discharge database from 1 January 2004 to 30 June 2015 to identify cases with fall and comorbidity using International Statistical Classification of Diseases and Related Health Problems, $9^{\text {th }}$ Revision, Australian Modification (ICD-9/10-AM) codes.

Results Over the study period, 16346 patients met the criteria of fall with hospital mortality rate of $4.3 \%$. The hospital mortality rates $(2.3 \%, 4.9 \%, 6.5 \%$, and $10.9 \%$ respectively, $\mathrm{P}<0.001)$ and hospital length of stay (geometric mean, 5.3, 6.1, 7.3, and 6.7 days, respectively, $\mathrm{P}<0.001$ ) increased consistently for patients with CCI ranging from none, low, moderate to high grade, respectively. Logistic regression model analysis showed that CCI (odds ratio, OR 5.7 high vs. none, $\mathrm{p}<0.001$ ) and male sex (OR 2.1, p < 0.001) were significant and independent predictors of hospital mortality. Similar results were also seen with hospital length of stay by zero-truncated negative binomial regression model analysis. Conclusion: The burden of fall is high in this older Asian population. Comorbidities and male sex were some of the most important contributors to hospital mortality and resource utilisation.

\section{CAN THE PROVISION OF A HOME HELP SERVICE FOR THE ELDERLY POPULATION REDUCE THE INCIDENCE OF FALL-RELATED INJURIES?}

\footnotetext{
${ }^{1,2}$ Carl Bonander, ${ }^{1,2}$ Johanna Gustavsson, ${ }^{1,2}$ Finn Nilson. 'Division of Risk Management, Department of Environmental and Life Sciences, Karlstad University, Sweden; ${ }^{2}$ Centre for Public Safety, Karlstad University, Sweden

\subsection{6/injuryprev-2016-042156.501}

Background Fall-related injuries are a global public health problem, especially in elderly populations. In this study, the effect of an intervention aimed at reducing the risk of falls in the homes of community-dwelling elderly persons was evaluated. The intervention, which involves home hazards reduction by providing a minor home help service, is provided in the majority of Swedish municipalities.
}

Methods Intention-to-treat effect estimates were derived using quasi-experimental time series intervention (ITS) analysis for immediate effects and a difference-in-discontinuity (RD) design for long term effects, and community-level estimates were pooled using meta-analysis. The outcome measure was the incidence of fall-related hospitalizations in the treatment population, the age of which varied by municipality ( $\geq 65$ years, $\geq 67$ years, $\geq 70$ years or $\geq 75$ years).

Results We found no statistically significant reductions in injury incidence in the ITS (IRR 1.01 [95\% CI: 0.98-1.05]) or RD (IRR 1.00 [95\% CI: 0.97-1.03]) analyses. The results are robust to several different model specifications, including segmented panel regression analysis with linear trend change and community fixed effects parameters.

Conclusions It is unclear whether absence of an effect is due to a low efficacy of the home hazards modifications provided, or a result of low utilisation. Additional studies of the effects on other quality of life measures are recommended before conclusions are drawn regarding the cost-effectiveness of the provision of home help services.

\section{PREVENTION OF ACCIDENTAL FALLS AMONG OLDER PEOPLE IN FINLAND - NATIONAL IKINÄ-PROGRAM}

${ }^{1}$ Satu Pajala, ${ }^{1}$ Laura Kolehmainen, ${ }^{1}$ Riitta Koivula, ${ }^{2}$ Mirka Råback, ${ }^{1}$ Anne Lounamaa. ${ }^{1}$ National Institute for Health and Welfare, Finland; ${ }^{2}$ Independent Researcher, Finland

\subsection{6/injuryprev-2016-042156.502}

Background In Finland, more than 900 older people $65+$ died due the fall in 2012. In addition, a fall was contributing factor of death of 770 persons 70 years and older. In 2012, costs of hospital inpatient care due to falls were close to EUR 400 million (THL injury database 2014).

Description of the problem Falls prevention has become extremely timely along with Finnish ageing policy prioritising older people living at their own home as long as possible. Despite vast quantity of evidence about falls prevention, the actions to put them in practice have not been as systematic and widespread as possible. Falls prevention needs to be an integral part of care and services for older people at all levels of care and among all service providers.

Results National program, called IKINÄ, was launched in 2006 to enhance dissemination and implementation of sustainable falls prevention in Finland. Aim of the program is to provide knowledge and stress the importance of falls prevention to policy-makers and other executive authorities in national level as well as municipalities. To enhance implementation of falls prevention IKINÄ-program produces evidence-based tools and materials for professionals and organisations working with older people.

During past ten years awareness of falls, their consequences and need for falls prevention have increased among professionals, both at executive level and those working in clinical practice, in the field of older people care and services in Finland. For example, several social and health care organisations have set the reduction of falls and fall injuries as their strategic goals. Thus, implementation of evidence-based falls prevention has become more systematic.

Conclusions Falls prevention requires to be continuous work and a joint effort of professionals working at all levels of care system of older people services. Sufficient resources should be allocated for falls prevention to ensure safe living at home for older people. 